\title{
Exhaled Nitric Oxide Differentiates Airway Diseases in the First Two Years of Life
}

\author{
CARMELO GABRIELE, EVELINE M. NIEUWHOF, ELS C. VAN DER WIEL, WARD HOFHUIS, HENRIETTE A. MOLL, \\ PETER J.F.M. MERKUS, AND JOHAN C. DE JONGSTE
}

\begin{abstract}
Department of Pediatric Respiratory Medicine [C.G., E.M.N., E.C.W., W.H., P.J.F.M.M., J.C.J.], Erasmus Medical Centre/Sophia Children's Hospital, Rotterdam, 3000 CB, the Netherlands; Generation R Study Group (http://www.generationr.nl) [C.G., H.A.M.], Erasmus Medical Centre, Sophia Children's Hospital, Rotterdam, 3015 GE, the Netherlands
\end{abstract}

\begin{abstract}
Fractional exhaled nitric oxide $\left(\mathrm{FE}_{\mathrm{NO}}\right)$ levels are increased in children and adults with asthma, whereas low levels have been found in cystic fibrosis and primary ciliary dyskinesia. The aim of this study was to investigate whether $\mathrm{FE}_{\mathrm{NO}}$ measurements could distinguish between children below the age of 2 with different airway diseases. $\mathrm{FE}_{\mathrm{NO}}$ measurements were performed in 118 infants aged between 4.6 and 25.2 mo: 74 infants with recurrent wheezing (RW), 24 with bronchopulmonary dysplasia (BPD), and 20 with cystic fibrosis $(\mathrm{CF})$. $\mathrm{FE}_{\mathrm{NO}}$ was measured also in 100 healthy controls aged between 1.1 and 7.7 mo. Geometric mean (95\% confidence interval) $\mathrm{FE}_{\mathrm{NO}}$ values were 10.4 (9.1-12.0) parts per billion (ppb) in healthy infants, $18.6(15.6-22.2)$ ppb in wheezy infants, 11.7 (8.216.8) ppb in BPD infants and $5.9(3.4-10.1) \mathrm{ppb}$ in $\mathrm{CF}$ infants. $\mathrm{FE}_{\mathrm{NO}}$ in wheezers was higher than in controls, BPD, and CF ( $p=0.009$, $p=0.038$, and $p<0.001$, respectively). Atopic wheezers showed higher $\mathrm{FE}_{\mathrm{NO}}$ than nonatopic wheezers $(p=0.04)$. CF infants had lower $\mathrm{FE}_{\mathrm{NO}}$ than healthy controls and BPD infants $(p=0.003$ and $p=0.043$, respectively). $\mathrm{FE}_{\mathrm{NO}}$ values in $\mathrm{BPD}$ and control infants were not different. We conclude that $\mathrm{FE}_{\mathrm{NO}}$ is helpful to differentiate various airway diseases already in the first $2 \mathrm{y}$ of life. (Pediatr Res
\end{abstract} 60: $461-465,2006)$

$\mathrm{T}$ The fractional concentration of nitric oxide in exhaled air $\left(\mathrm{FE}_{\mathrm{NO}}\right)$ has been suggested as a marker of bronchial eosinophilic inflammation. Increased $\mathrm{FE}_{\mathrm{NO}}$ levels have been found in asthmatic adults (1) and children with symptoms of asthma and atopy (2). Guidelines for the measurement of $\mathrm{FE}_{\mathrm{NO}}$ are available for both adults and children $(3,4)$, and normal values for healthy children between 4 and $17 \mathrm{y}$ of age have been recently published (5). Although in the last decade there has been a growing interest in measuring $\mathrm{FE}_{\mathrm{NO}}$ in noncooperative young children as well, few studies have investigated $\mathrm{FE}_{\mathrm{NO}}$ as a marker of bronchial inflammation in children below the age of $2 \mathrm{y}$. It has been shown that infants with recurrent wheeze have elevated levels of $\mathrm{FE}_{\mathrm{NO}}$ during exacerbations that rapidly decrease after steroid therapy (6),

Received January 11, 2006; accepted May 22, 2006.

Correspondence: Johan C. de Jongste, M.D., Ph.D., Erasmus University Medical Centre/Sophia Children's Hospital, PO Box 2060, 3000 CB The Netherlands; e-mail: j.c.dejongste@erasmusmc.nl

Partial data of the present article were published as an abstract and presented at the European Respiratory Society Congress, Copenhagen, 2005 (Eur Respir J 2005; 26: Suppl. 49, 674s)

C.G. was supported by a grant of the Dutch Asthma Foundation.

DOI: 10.1203/01.pdr.0000238242.39881.64 suggesting that eosinophilic airway inflammation is present in early childhood wheeze. Low $\mathrm{FE}_{\mathrm{NO}}$ levels have been found in infants with $\mathrm{CF}(7)$, primary ciliary dyskinesia (8) and rhinorrhea (9). A recent study by Baraldi and co-workers (10) showed that school-age children with BPD and airflow limitation had lower $\mathrm{FE}_{\mathrm{NO}}$ levels than healthy matched controls and asthmatic children, suggesting that airflow limitation in children with BPD might not be related to ongoing inflammation as is the case in asthma. It is well known that infants with BPD have an early inflammatory response followed by chronic inflammation and airways remodeling (11-13). Only one study previously reported high $\mathrm{FE}_{\mathrm{NO}}$ levels in infants with chronic lung disease (14).

The aim of the present study was to measure $\mathrm{FE}_{\mathrm{NO}}$ in infants below the age of $2 \mathrm{y}$ and to evaluate whether $\mathrm{FE}_{\mathrm{NO}}$ could be used to differentiate airways diseases in the first $2 \mathrm{y}$ of life.

\section{METHODS}

Subjects. $\mathrm{FE}_{\mathrm{NO}}$ measurements were conducted in 118 infants with different respiratory diseases, who either participated in other clinical trials (15) or were referred to the Department of Pediatric Respiratory Medicine, Sophia Children's Hospital in Rotterdam, to perform lung function tests as part of the routine patient care. As the control group we took a random sample of 100 healthy infants participating in an ongoing birth cohort study (16). All these infants had been free of significant respiratory symptoms since birth, and $\mathrm{FE}_{\mathrm{NO}}$ measurements were performed at about $6 \mathrm{wk}$ or 6 mo of age.

Parents gave written informed consent. The Medical Ethical Committee of the Erasmus University Medical Centre approved the study.

Infants with $R \boldsymbol{W}(\boldsymbol{n}=74)$. RW was defined as 3 or more reported wheezing episodes, or at least 1 period of persistent wheezing longer than 2 mo, but not continuously present from birth on. Fifty-three infants had a high risk for atopy, defined as parental history of allergy, asthma, eczema or hay fever, or had eczema, and 21 were nonatopic. Five infants had been treated with inhaled corticosteroids before the study.

Infants with BPD $(\boldsymbol{n}=24)$. BPD was defined as clinical signs of respiratory distress, chest radiograph abnormalities, and oxygen dependence at $28 \mathrm{~d}$ (11). Infants were born at gestational age $<32 \mathrm{wk}$ and had a birth weight $<2000 \mathrm{~g}$. During the month before the study, five infants had been using both inhaled corticosteroids and beta- 2 agonists and three used corticosteroids only. At the time of the study, none of the infants required oxygen treatment.

Infants with $\boldsymbol{C F}(\boldsymbol{n}=20)$. CF was diagnosed on the basis of typical symptoms, a positive sweat test, and two DNA CF mutations. Eight infants had been receiving antibiotic treatment during the week before the measure-

Abbreviations: BPD, bronchopulmonary dysplasia; CF, cystic fibrosis; FRC, functional residual capacity; $\mathbf{F E}_{\mathbf{N O}}$, fractional exhaled nitric oxide; RW, recurrent wheezing; $\dot{\mathbf{V}}_{\mathbf{m a x}} \mathbf{F R C}$, forced expiratory flow at functional residual capacity 
ments. At the time of testing all children were clinically stable and there were no signs of acute airway infection.

Infant lung function tests. Lung function measurements were performed between 6 and 25 mo corrected age, when the infants were free from acute respiratory symptoms. Infants refrained from using beta- 2 agonists in the $24 \mathrm{~h}$ before testing. Infants were sedated with choral hydrate $(50-100 \mathrm{mg} / \mathrm{kg})$. Functional residual capacity (FRCp) was measured by means of a modified whole body plethysmograph (Jaeger, Würzburg, Germany). The mean FRCp of three to five technically acceptable measurements was recorded and expressed as $\mathrm{Z}$ score (17). $\dot{\mathrm{V}}_{\max } \mathrm{FRC}$ was assessed using the end-tidal rapid thoracoabdominal compression technique (custom-made equipment; Department for Experimental Medical Instrumentation, Erasmus University Medical Centre, Rotterdam, the Netherlands). The mean $\dot{\mathrm{V}}_{\max } \mathrm{FRC}$ of three to five technically acceptable measurements was recorded and expressed as Z score $(17,18)$. Equipment and procedures were in accordance with recently published guidelines $(18,19)$. Measurement of airway resistance was performed by means of the interrupter technique (MicroRint; MicroMedical Ltd., Rochester, UK).

$\boldsymbol{F E} \boldsymbol{E}_{\text {No }}$ measurements. Exhaled air samples were collected with a face mask placed over infants' nose and mouth during tidal breathing while infants with lung diseases were sedated (50-100 mg/kg chloral hydrate). Because of medical ethical reasons, no chloral hydrate was used in healthy control infants. The face mask was connected to a two-way nonrebreathing valve (Hans Rudolph Inc., Kansas City, MO) that allows inspiration of NO-free air from an NO-inert 750-mL Mylar balloon to avoid contamination by ambient NO. This balloon was connected to the inspiratory port if ambient levels were $>10$ parts per billion ( $\mathrm{ppb}$ ), allowing washout of the dead space of the lungs. Ten NO-free breaths were sufficient for this purpose as suggested by current guidelines (4). Exhaled breath samples were collected into an NO-inert 150-mL Mylar balloon fitted with the expiratory port, and five breaths were collected in the sampling balloon. Then $\mathrm{FE}_{\mathrm{NO}}$ was analyzed by a fast response NO analyzer (Sievers $280 \mathrm{~B}$, Boulder, CO) within $1 \mathrm{~h}$ of the measurement. The analyzer was calibrated in accordance to the manufacturer instructions with 0 ppb and 200 ppb NO certified calibration gas (Hoek Loos, Barendrecht, the Netherlands). All $\mathrm{FE}_{\mathrm{NO}}$ measurements were performed before lung function tests. In healthy infants, $\mathrm{FE}_{\mathrm{NO}}$ measurements were also performed with the face mask placed over infants' nose and mouth, during quiet tidal breathing with infants in supine position, but without the use of sedation. A $\mathrm{FE}_{\mathrm{NO}}$ measurement was considered successful if exhaled air was sampled during quiet tidal breathing, if the face mask was tightly fitted to nose and mouth during the whole procedure, and if at least five breaths were collected.

Before each $\mathrm{FE}_{\mathrm{NO}}$ measurement, the ambient $\mathrm{NO}$ concentration was recorded.

Data analysis. $\mathrm{FE}_{\mathrm{NO}}$ values were log-transformed to obtain a near-normal distribution and analyzed by means of parametric tests. The $\log -\mathrm{FE}_{\mathrm{NO}}$ values were subsequently back-transformed and expressed as geometric means with their $95 \%$ confidence intervals $(95 \% \mathrm{CI})$. Univariate ANOVA was used to compare demographic characteristics and lung function parameters in the groups of infants. Regression analysis was used to evaluate the relation between $\mathrm{FE}_{\mathrm{NO}}$ and ambient $\mathrm{NO}$ concentrations. Comparisons between the groups of diseased infants and the healthy control group were performed by linear regression analysis, controlling for age, length, and weight. As infants with lung diseases had different degrees of airflow limitation, a linear regression analysis was performed with $\log -\mathrm{FE}_{\mathrm{NO}}$ as dependent variable, while controlling for age, weight, length, and lung function parameters, including tidal volume and breathing frequency, of the three groups of diseased infants.

The area under the receiver operating characteristic curve (ROC curve) was calculated to evaluate the accuracy of $\mathrm{FE}_{\mathrm{NO}}$ measurements in differentiating the diagnostic groups.

Proportions were compared by $\chi^{2}$ test. Correlations were evaluated by Pearson's test if the variables were normally distributed, otherwise the Spearman's coefficient was calculated. $t$ Test was used to compare $\mathrm{FE}_{\mathrm{NO}}$ values in infants with high risk of atopy and nonatopic infants and to compare
$\mathrm{FE}_{\mathrm{NO}}$ between infants who used medications and infants who did not. Two-tailed $p$ values of $<0.05$ were considered significant.

\section{RESULTS}

All anthropometric characteristics, except for gender ratio, were significantly different between the four groups of infants, as outlined in Table 1.

Lung function tests and $\mathrm{FE}_{\mathrm{NO}}$ measurements were successfully performed in all infants. Lung function parameters differed between the groups and are reported in Table 2 together with $\mathrm{FE}_{\mathrm{NO}}$ values.

Log- $\mathrm{FE}_{\mathrm{NO}}$ values were significantly related to weight (Pearson's coefficient $=0.243 ; p=0.008$ ) and length (Pearson's coefficient $=0.221 ; p=0.016$ ) only within groups of infants with wheeze, BPD and CF (Fig. 1, $A$ and $B$ ). Age was significantly related to $\mathrm{FE}_{\mathrm{NO}}$ when considering the groups altogether (Spearman's coefficient $=0.208 ; p=0.002$ ). No relation was found between ambient $\mathrm{NO}$ and measured $\mathrm{FE}_{\mathrm{NO}}$ in any group of infants.

Adjusting for age, length, and weight, and in patient groups also for lung function parameters, the linear regression model showed that $\mathrm{FE}_{\mathrm{NO}}$ values in wheezy infants were higher than in controls [mean difference $(95 \% \mathrm{CI}) \mathrm{FE}_{\mathrm{NO}}=1.6(1.1-2.3)$ $\mathrm{ppb} ; p=0.009$ ], higher than in BPD infants [mean difference $\left.(95 \% \mathrm{CI}) \mathrm{FE}_{\mathrm{NO}}=1.9(1.0-3.5) \mathrm{ppb} ; p=0.038\right]$ and higher than in $\mathrm{CF}$ infants [mean difference $(95 \% \mathrm{CI}) \mathrm{FE}_{\mathrm{NO}}=3.6$ (2.2-6.0) ppb; $p<0.001]$. Atopic and high-risk wheezy infants $(n=53)$ had higher geometric mean $\mathrm{FE}_{\mathrm{NO}}$ than nonatopic wheezy infants $(n=21)(20.8 \mathrm{ppb}$ and $14.0 \mathrm{ppb}$, respectively; $p=0.04$ ), whereas $\mathrm{FE}_{\mathrm{NO}}$ in nonatopic wheezers was not different from healthy controls and BPD infants. CF infants showed lower $\mathrm{FE}_{\mathrm{NO}}$ than healthy controls and $\mathrm{BPD}$ infants [mean difference $(95 \% \mathrm{CI}) \mathrm{FE}_{\mathrm{NO}}=2.0(1.3-3.1) \mathrm{ppb}$; $p=0.003$ and 1.9 (1.0-3.6); $p=0.043$, respectively], whereas $\mathrm{FE}_{\mathrm{NO}}$ was similar between BPD infants and the control group [mean difference $(95 \% \mathrm{CI}) \mathrm{FE}_{\mathrm{NO}}=1.0(0.7-$ 1.5) $\mathrm{ppb} ; p=0.8]$ (Fig. 2).

The area under the ROC curve of wheezy infants compared with healthy controls was $0.710(p<0.001)$. A cut-off value of $14.1 \mathrm{ppb}$ would give a sensitivity of $61 \%$ and specificity of $63 \%$, whereas $10.1 \mathrm{ppb}$ would give a sensitivity of $82 \%$ and specificity of $51 \%$ (Fig. 3). The areas under the ROC curves for the other diagnostic groups were 0.567 for BPD versus controls $(p=0.3)$ and 0.374 for CF versus controls $(p=$ 0.075).

A significant correlation was found between $\mathrm{FE}_{\mathrm{NO}}$ and FRCp Z score in the recurrent wheezers (Pearson's coefficient

Table 1. Study population

\begin{tabular}{lcccr} 
& $\begin{array}{c}\text { Healthy controls } \\
(n=100)\end{array}$ & $\begin{array}{c}\text { RW } \\
(n=74)\end{array}$ & BPD & CF \\
& $(n=24)$ & $10.8(4.6-24.0)$ & $12.5(6.1-19.6)$ \\
Age (mo) & $3.9(1.1-7.7)$ & $13.4(5.6-25.2)$ & $48 / 26$ & $9 / 11$ \\
Males/females & $62 / 38$ & $10.4(0.2)$ & $7.3(0.3)$ & $8.6(0.4)$ \\
Weight $(\mathrm{kg})$ & $6.0(0.2)$ & $77.4(0.7)$ & $68.8(1.3)$ & $72.9(1.2)$ \\
Length (cm) & $61.3(0.7)$ & & \\
\hline
\end{tabular}

Age is reported as mean (range). Weight and length are presented as mean (SEM). Age, weight, and length were significantly different between the four groups of infants $(p<0.001$ for all characteristics on univariate ANOVA). 
Table 2. Lung function parameters and $F E_{N O}$ values in different groups of infants

\begin{tabular}{|c|c|c|c|c|}
\hline & $\begin{array}{l}\text { Healthy controls } \\
\quad(n=100)\end{array}$ & $\begin{array}{c}\mathrm{RW} \\
(n=74)\end{array}$ & $\begin{array}{c}\text { BPD } \\
(n=24)\end{array}$ & $\begin{array}{c}\text { CF } \\
(n=20)\end{array}$ \\
\hline $\mathrm{FE}_{\mathrm{NO}}(\mathrm{ppb})$ & $10.4(9.1-12.0)$ & $18.6(15.6-22.2)$ & $11.8(8.2-16.8)$ & $5.9(3.4-10.1)$ \\
\hline FRCp (mL/kg) & ND & $23.4(0.5)$ & $29(1.6)$ & $27.6(1.3)$ \\
\hline$\dot{\mathrm{V}}_{\max } \mathrm{FRC},(\mathrm{mL} / \mathrm{s})$ & ND & $164.2(8.6)$ & $81.8(7.3)$ & $191.6(20.6)$ \\
\hline$\dot{\mathrm{V}}_{\max } \mathrm{FRC} \mathrm{Z}$ score & & $-1.6(0.1)^{*}$ & $-2.1(0.1) \S$ & $-0.9(0.2)$ \\
\hline $\operatorname{Rint}(\mathrm{kPa} / \mathrm{L} / \mathrm{s})$ & ND & $2.9(0.1)$ & $4.0(0.3)$ & $2.7(0.3)$ \\
\hline
\end{tabular}

Values are expressed as mean (SEM). $\mathrm{FE}_{\mathrm{NO}}$ values are reported as geometric mean $(95 \% \mathrm{CI})$.

Rint, airway resistance measured by means of the interrupter technique; ND, measurement not done.

$* p=0.005$ compared with $\mathrm{CF} ; * * p=0.001$ compared with $\mathrm{RW} ; \S p=0.02$ compared with $\mathrm{RW}$; and $p<0.001$ compared with $\mathrm{CF}$.
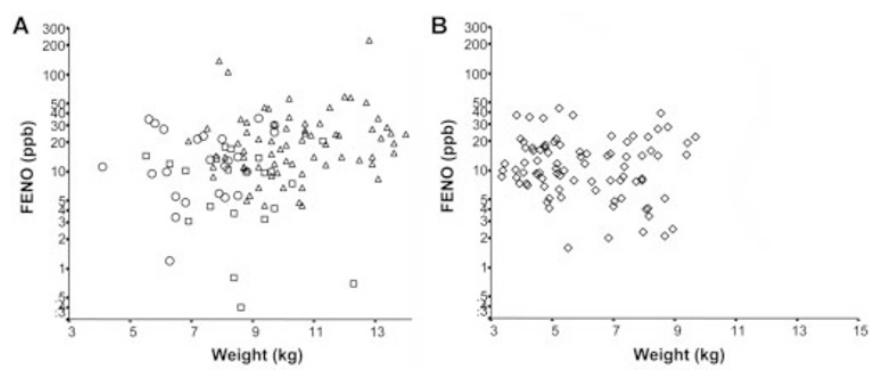

Figure 1. (A) Relation between $\mathrm{FE}_{\mathrm{NO}}$ (represented on a log-scale) and weight within groups of diseased infants. RW $(\triangle)$, BPD $(\bigcirc)$, CF $(\square)$. (B) Relation between $\mathrm{FE}_{\mathrm{NO}}$ (represented on a log-scale) and weight in the group of healthy infants $(\diamond)$.

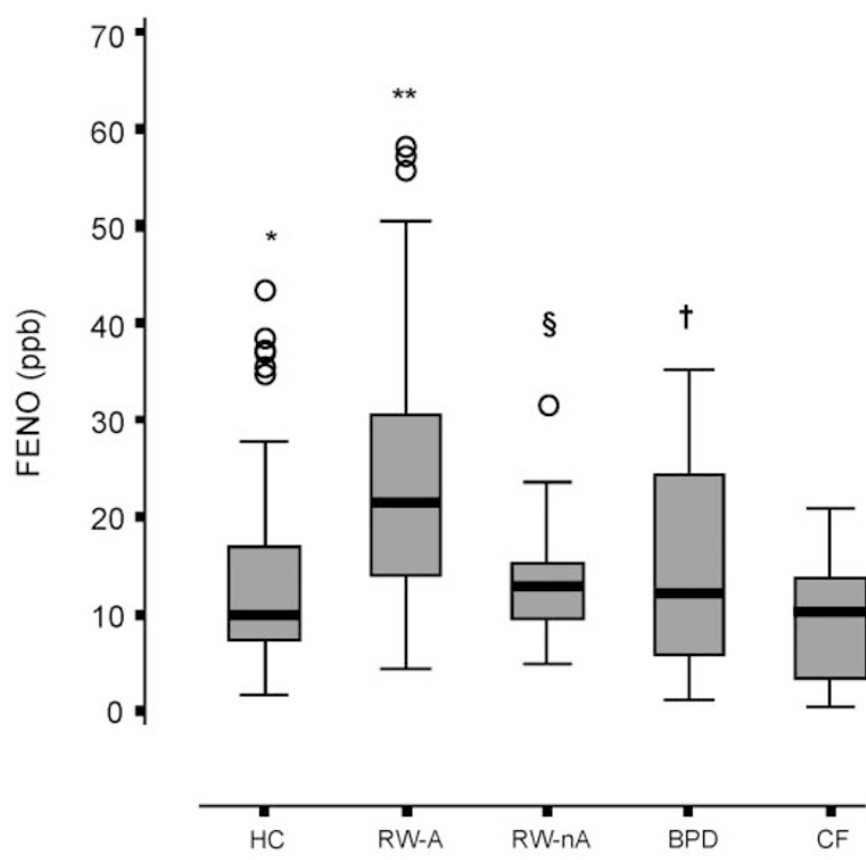

Figure 2. $\mathrm{FE}_{\mathrm{NO}}$ levels in different groups of infants. Median is line in box, and box limits represent 25 th and 75 th percentiles. Whiskers extend to 10th and 90th percentiles. Circles represent outliers. HC, healthy controls $(n=$ $100)$; RW-A, recurrent wheezing, atopic $(n=53)$; RW-nA recurrent wheezing, nonatopic $(n=21)$; BPD $(n=24)$; CF $(n=20) . * p=0.003$ compared with RW-A and to CF. $* * p=0.04$ compared with RW-nA; $p=0.005$ compared with BPD; $p<0.001$ compared with CF. $\$ p<0.001$ compared with $\mathrm{CF} . \dagger p=0.043$ compared with $\mathrm{CF}$.

$=0.252, p=0.037$ ) (Fig. 4). No correlation was found between $\mathrm{FE}_{\mathrm{NO}}$ and lung function parameters within all other groups of infants.

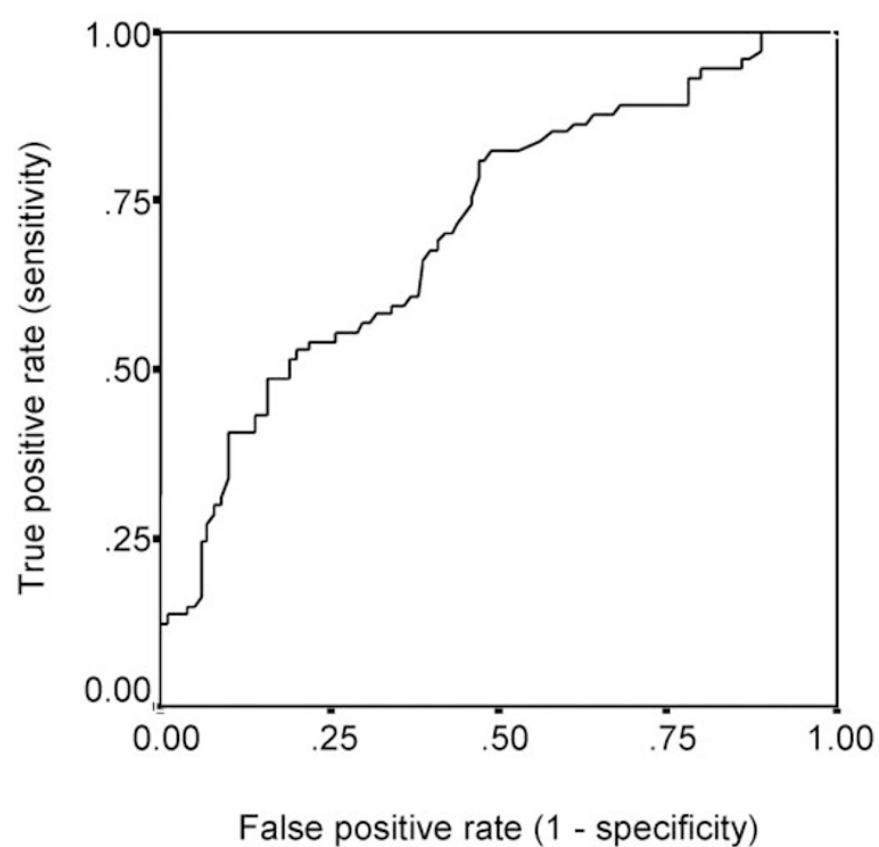

Figure 3. ROC curve analysis of wheezy infants compared with controls.

No difference was obvious between $\mathrm{FE}_{\mathrm{NO}}$ of infants who used either inhaled corticosteroids ( $\mathrm{RW}=18.5 \mathrm{ppb}$ and $\mathrm{BPD}$ $=14.4 \mathrm{ppb})$ or antibiotics $(\mathrm{CF}=5.3 \mathrm{ppb})$, when compared with the same category group of infants who did not use such medications $(\mathrm{RW}=18.6 \mathrm{ppb}, \mathrm{BPD}=10.6 \mathrm{ppb}$, and $\mathrm{CF}=6.3$ $\mathrm{ppb})$. However, numbers were small and no further calculation was performed.

\section{DISCUSSION}

We evaluated $\mathrm{FE}_{\mathrm{NO}}$ in infants with various airway diseases. We found that $\mathrm{FE}_{\mathrm{NO}}$ values in wheezy infants were higher and in $\mathrm{CF}$ infants lower than in controls. $\mathrm{FE}_{\mathrm{NO}}$ values in $\mathrm{BPD}$ and control infants were not significantly different. We also found that $\mathrm{FE}_{\mathrm{NO}}$ was significantly higher in wheezy infants with high risk of atopy, compared with nonatopic wheezy infants.

The relation between $\mathrm{FE}_{\mathrm{NO}}$ and various airway diseases has extensively been studied in adults and older children. However, few studies evaluated $\mathrm{FE}_{\mathrm{NO}}$ in relatively large groups of infants with different airway diseases while taking lung function parameters, tidal volume, and breathing frequency into account. Moreover, we used a simple technique to collect exhaled air that may easily be applied in practice and does not 


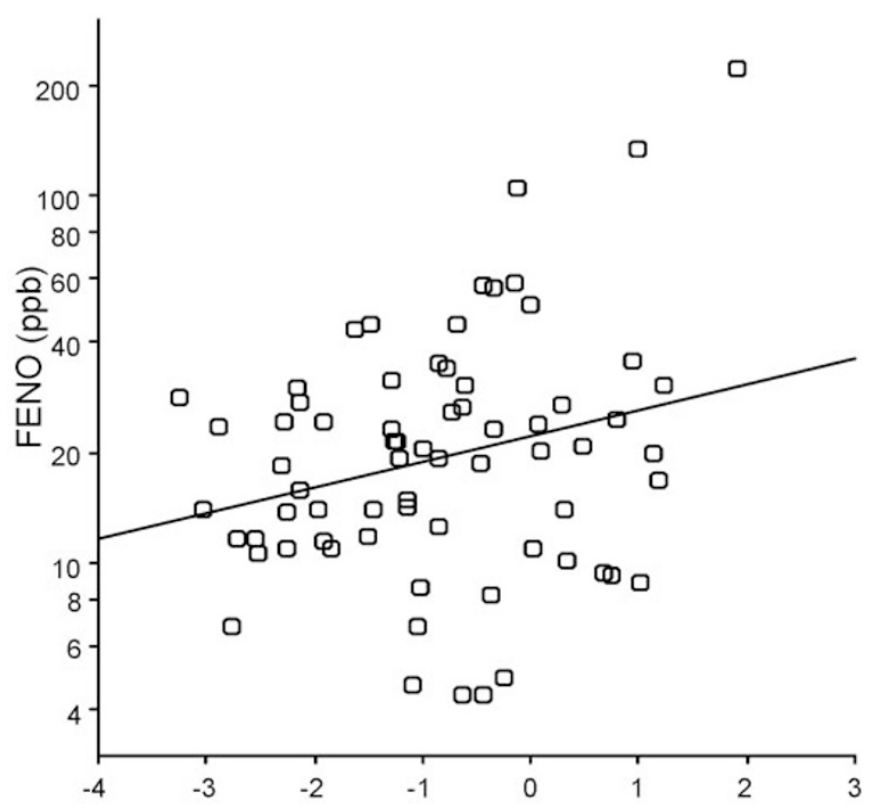

FRCp Z-score

Figure 4. $\mathrm{FE}_{\mathrm{NO}}$ values (represented on a log scale) were correlated to FRCp $\mathrm{Z}$ score in infants with RW $(n=74)$. $\mathrm{FE}_{\mathrm{NO}}=1.346+0.069 \mathrm{FRCp} \mathrm{Z}$ score $(p=0.037)$.

require a sophisticated infant lung function lab and specialized staff (20).

Despite the fact that we used a relatively simple method, our results confirm the findings of Wildhaber et al. (21) and Franklin et al. (22), who showed that wheezy infants had higher $\mathrm{FE}_{\mathrm{NO}}$ than healthy controls. We found that atopic wheezers had higher $\mathrm{FE}_{\mathrm{NO}}$ than nonatopic wheezers and healthy controls, whereas no difference was obvious between nonatopic wheezers and healthy controls. This suggests that eosinophilic airway inflammation is already present in these infants with atopic wheeze. In agreement with the study of Mappa et al. (23), we also found a correlation between $\mathrm{FE}_{\mathrm{NO}}$ levels and FRCp in wheezy infants, suggesting that air trapping in the lungs is related to airway inflammation.

In a recent study, Baraldi and co-workers (10) found low levels of $\mathrm{FE}_{\mathrm{NO}}$ in school-age BPD survivors and speculated that the defective NO synthesis and/or diffusion in the airway lumen could be either a consequence of the epithelial damage occurring in the early phases of BPD or could be attributed to a disturbed vascular growth, with a reduction in the pulmonary vascular bed (24). Although it has been shown that BPD children have bronchial inflammation early in life, in our study we found that $\mathrm{FE}_{\mathrm{NO}}$ did not differ between BPD infants and healthy controls. The inflammation pathway in the airways of BPD seems to be mediated by neutrophilic granulocytes $(25,26)$, and this may explain our findings, as $\mathrm{FE}_{\mathrm{NO}}$ has been shown to reflect eosinophilic rather than neutrophilic inflammation of the airways.

Our results confirm the findings of Elphick et al. (7), showing that $\mathrm{CF}$ infants have lower $\mathrm{FE}_{\mathrm{NO}}$ levels than healthy controls. The mechanisms underlying the low $\mathrm{FE}_{\mathrm{NO}}$ levels in CF subjects have been hypothesized to be due either to excess secretions in $\mathrm{CF}$ airways that might inhibit the diffusion of $\mathrm{NO}$ into the airway lumen, or to a primary defect in NO production. Since we measured $\mathrm{FE}_{\mathrm{NO}}$ in an early stage of the disease and only eight CF infants had needed antibiotics for previous lung infections, our results would support the findings of Steagall et al. (27) that nitric oxide synthase 2 (NOS2) expression is regulated by the presence of active CFTR.

It has been previously shown that $\mathrm{FE}_{\mathrm{NO}}$ correlates with age of children between 4 and 17 y (5). A correlation between $\mathrm{FE}_{\mathrm{NO}}$ and age has been also reported in children below the age of 2 only when $\mathrm{FE}_{\mathrm{NO}}$ was measured off-line during tidal breathing, with an increase of $0.1 \mathrm{ppb}$ per week of age (22). We confirm the previous findings, although the regression model showed a higher increase of $\mathrm{FE}_{\mathrm{NO}}$ per week of age in our study than previously reported ( $0.2 \mathrm{ppb}$ per week of age). As healthy infants in our study had $\mathrm{FE}_{\mathrm{NO}}$ measured at the age of $6 \mathrm{wk}$ or $6 \mathrm{mo}$, age differences between controls and diseased infants were present. Significant differences were also present in other characteristics between diagnostic groups, such as length and weight, and these could have affected the results of our study. However, the regression model showed that differences in $\mathrm{FE}_{\mathrm{NO}}$ values between groups remained significant also after controlling for such variables, indicating that the variability of $\mathrm{FE}_{\mathrm{NO}}$ between groups cannot be attributed only to the differences in anthropometric characteristics of the study subjects.

A possible limitation of our study is the use of sedation for the $\mathrm{FE}_{\mathrm{NO}}$ measurements in the diseased groups, but not in healthy controls. In a previous study, Franklin and co-workers (28) found a significant difference in $\mathrm{FE}_{\mathrm{NO}}$ levels between awake and sedated infants, with the latter group having lower $\mathrm{FE}_{\mathrm{NO}}$ values than the former. If this is the case, the $\mathrm{FE}_{\mathrm{NO}}$ values of the control group in our study might have been overestimated. However, in this case the differences in our study between controls and wheezy infants might have been underestimated. Another limitation of our study was that we collected mixed oral and nasal $\mathrm{FE}_{\mathrm{NO}}$ by collecting expired gas in a single-compartment face mask, therefore we could not distinguish between NO derived from upper and lower airways (29). This might introduce variability and explain some of the overlap between groups. This would also imply that our study underestimates any differences between groups. However, it has been shown that both nasal and oral NO levels reflect mixed exhaled NO in infants (28) and techniques to avoid nasal contamination of exhaled air in infants require complicated and demanding equipment, unlikely to become useful in practice $(30,31)$. Also, standardization for expiratory flow in infants is technically possible, but difficult (20), and may be unnecessary. Moreover, such overlap is a characteristic of any lung function test in a cross-sectional study, but this does not by definition invalidate the findings that may well be clinically useful and should be further evaluated for their merits, e.g. in follow-up studies. We did not measure lung function in healthy infants, therefore we could not compare lung function parameters in the control group to the other groups of diseased infants. The healthy infants participate in an ongoing birth cohort study and it was not ethically permitted to sedate before lung function tests. However, in this study 
we also found that $\mathrm{FE}_{\mathrm{NO}}$ values were significantly different between groups of infants with pulmonary diseases, showing the potential utility of $\mathrm{FE}_{\mathrm{NO}}$ in differentiating airway diseases already in the first $2 \mathrm{y}$ of life.

As in the last decade there has been a growing interest in measuring $\mathrm{FE}_{\mathrm{NO}}$ also in noncooperative children, our findings have important implications. The early detection of the inflammatory pattern underlying different airway diseases could lead to a better targeted management of such children already in the first years of life. This is especially important for BPD infants, who share some clinical and spirometric features with bronchial asthma and are often treated with asthma medication including inhaled corticosteroids.

We conclude that $\mathrm{FE}_{\mathrm{NO}}$ measurements can be performed early in life using a simple methodology and can be considered potentially useful to differentiate between various airway diseases in children below the age of $2 \mathrm{y}$. It may be possible to improve the technique to evaluate the utility of $\mathrm{FE}_{\mathrm{NO}}$ measurements at individual level. Further studies should explore feasible techniques to optimize $\mathrm{FE}_{\mathrm{NO}}$ measurements in infants, and the role of $\mathrm{FE}_{\mathrm{NO}}$ in follow-up studies of disease monitoring or guiding treatment in infants and young children with pulmonary diseases.

\section{REFERENCES}

1. Alving K, Weitzberg E, Lundberg JM 1993 Increased amount of nitric oxide in exhaled air of asthmatics. Eur Respir J 6:1368-1370

2. Brussee JE, Smit HA, Kerkhof M, Koopman LP, Wijga AH, Postma DS, Gerritsen J, Grobbee DE, Brunekreef B, de Jongste JC 2005 Exhaled nitric oxide in 4-year-old children: relationship with asthma and atopy. Eur Respir J 25:455-461

3. American Thoracic Society 2005 European Respiratory Society 2005 ATS/ERS Recommendations for Standardized Procedures for the Online and Offline Measurement of Exhaled Lower Respiratory Nitric Oxide and Nasal Nitric Oxide. Am J Respir Crit Care Med 171:912-930

4. Baraldi E, de Jongste JC 2002 Measurement of exhaled nitric oxide in children, 2001. Eur Respir J 20:223-237

5. Buchvald F, Baraldi E, Carraro S, Gaston B, De Jongste J, Pijnenburg MW, Silkoff PE, Bisgaard H 2005 Measurements of exhaled nitric oxide in healthy subjects age 4 to 17 years. J Allergy Clin Immunol 115:1130-1136

6. Baraldi E, Dario C, Ongaro R, Scollo M, Azzolin NM, Panza N, Paganini N, Zacchello F 1999 Exhaled nitric oxide concentrations during treatment of wheezing exacerbation in infants and young children. Am J Respir Crit Care Med 159:12841288

7. Elphick HE, Demoncheaux EA, Ritson S, Higenbottam TW, Everard ML 2001 Exhaled nitric oxide is reduced in infants with cystic fibrosis. Thorax 56:151-152

8. Karadag B, James AJ, Gultekin E, Wilson NM, Bush A 1999 Nasal and lower airway level of nitric oxide in children with primary ciliary dyskinesia. Eur Respir J 13:1402-1405

9. Franklin PJ, Turner SW, Hall GL, Moeller A, Stick SM 2005 Exhaled nitric oxide is reduced in infants with rhinorrhea. Pediatr Pulmonol 39:117-119
10. Baraldi E, Bonetto G, Zacchello F, Filippone M 2005 Low exhaled nitric oxide in school-age children with bronchopulmonary dysplasia and airflow limitation. Am J Respir Crit Care Med 171:68-72

11. Jobe AH, Bancalari E 2001 Bronchopulmonary dysplasia. Am J Respir Crit Care Med 163:1723-1729

12. Allen J, Zwerdling R, Ehrenkranz R, Gaultier C, Geggel R, Greenough A, Kleinman R, Klijanowicz A, Martinez F, Ozdemir A, Panitch HB, Nickerson B, Stein MT, Tomezsko J, Van Der Anker J 2003 Statement on the care of the child with chronic lung disease of infancy and childhood. Am J Respir Crit Care Med 168:356-396

13. Ozdemir A, Brown MA, Morgan WJ 1997 Markers and mediators of inflammation in neonatal lung disease. Pediatr Pulmonol 23:292-306

14. Leipala JA, Williams O, Sreekumar S, Cheeseman P, Rafferty GF, Hannam S, Milner A, Greenough A 2004 Exhaled nitric oxide levels in infants with chronic lung disease. Eur J Pediatr 163:555-558

15. Hofhuis W, van der Wiel EC, Nieuwhof EM, Hop WC, Affourtit MJ, Smit FJ, Vaessen-Verberne AA, Versteegh FG, de Jongste JC, Merkus PJ 2005 Efficacy of fluticasone propionate on lung function and symptoms in wheezy infants. Am J Respir Crit Care Med 171:328-333

16. Hofman A, Jaddoe VW, Mackenbach JP, Moll HA, Snijders RF, Steegers EA, Verhulst FC, Witteman JC, Buller HA 2004 Growth, development and health from early fetal life until young adulthood: the Generation R Study. Paediatr Perinat Epidemiol 18:61-72

17. Tepper RS, Reister T 1993 Forced expiratory flows and lung volumes in normal infants. Pediatr Pulmonol 15:357-361

18. Sly PD, Tepper R, Henschen M, Gappa M, Stocks J 2000 Tidal forced expirations. ERS/ATS Task Force on Standards for Infant Respiratory Function Testing. European Respiratory Society/American Thoracic Society. Eur Respir J 16:741-748

19. Stocks J, Godfrey S, Beardsmore C, Bar-Yishay E, Castile R 2001 Plethysmographic measurements of lung volume and airway resistance. ERS/ATS Task Force on Standards for Infant Respiratory Function Testing. European Respiratory Society/ American Thoracic Society. Eur Respir J 17:302-312

20. Hall GL, Reinmann B, Wildhaber JH, Frey U 2002 Tidal exhaled nitric oxide in healthy, unsedated newborn infants with prenatal tobacco exposure. J Appl Physiol 92:59-66

21. Wildhaber JH, Hall GL, Stick SM 1999 Measurements of exhaled nitric oxide with the single-breath technique and positive expiratory pressure in infants. Am J Respir Crit Care Med 159:74-78

22. Franklin PJ, Turner SW, Mutch RC, Stick SM 2004 Comparison of single-breath and tidal breathing exhaled nitric oxide levels in infants. Eur Respir J 23:369-372

23. Mappa L, Cardinale F, Camodeca R, Tortorella ML, Pietrobelli A, Armenio L, Boner AL 2005 Exhaled nitric oxide and air trapping correlation in asthmatic children. Allergy 60:1436-1439

24. Abman SH 2001 Bronchopulmonary dysplasia: "a vascular hypothesis." Am J Respir Crit Care Med 164:1755-1756

25. Carlton DP, Albertine KH, Cho SC, Lont M, Bland RD 1997 Role of neutrophils in lung vascular injury and edema after premature birth in lambs. J Appl Physiol 83:1307-1317

26. Ferreira PJ, Bunch TJ, Albertine KH, Carlton DP 2000 Circulating neutrophil concentration and respiratory distress in premature infants. J Pediatr 136:466-472

27. Steagall WK, Elmer HL, Brady KG, Kelley TJ 2000 Cystic fibrosis transmembrane conductance regulator-dependent regulation of epithelial inducible nitric oxide synthase expression. Am J Respir Cell Mol Biol 22:45-50

28. Franklin PJ, Turner SW, Mutch RC, Stick SM 2004 Measuring exhaled nitric oxide in infants during tidal breathing: methodological issues. Pediatr Pulmonol 37:24-30

29. Artlich A, Busch T, Lewandowski K, Jonas S, Gortner L, Falke KJ 1999 Childhood asthma: exhaled nitric oxide in relation to clinical symptoms. Eur Respir J 13:13961401

30. Martinez T, Weist A, Williams T, Clem C, Silkoff P, Tepper RS 2003 Assessment of exhaled nitric oxide kinetics in healthy infants. J Appl Physiol 94:2384 2390

31. Artlich A, Jonsson B, Bhiladvala M, Lonnqvist PA, Gustafsson LE 2001 Single breath analysis of endogenous nitric oxide in the newborn. Biol Neonate 79:21-26 